\title{
THICK FILM CAPACITOR MATERIALS OF THE POWDER-GLASS BINARY SYSTEMS AND THEIR DIELECTRIC PROPERTIES
}

\author{
AKIRA IKEGAMI, HIDEO ARIMA and KATSUO ABE \\ Production Engineering Research Laboratory, Hitachi Ltd., Totsuka-ku, Yohohama, 244 Japan \\ (Received November 25, 1980)
}

\begin{abstract}
Descriptions are given of the fundamental dielectric properties of the thick film binary system, composed of dielectric powder and glass, in relation to the effect of bulk properties of the constituent electrode composition in preventing a decrease in breakdown voltage with time and the effect of glass passivation on the reliability of thick film capacitors.
\end{abstract}

\section{INTRODUCTION}

Many trials ${ }^{1-8}$ to incorporate a thick film capacitor onto thick film hybrid ICs have been made in order to reduce the size, number of interconnections and cost. However, a narrow choice of characteristics and poor reliability of thick film capacitor materials have prevented putting them into production. The objective of this study is to clarify the possibility and limitation of the thick film capacitor materials, in the powder-glass binary system.

\section{EXPERIMENTAL PROCEDURES}

The dielectric powders were prepared by the usual ceramic techniques. The desired amount of the constituent oxides and carbonates were mixed, calcined at 800 to $1050^{\circ} \mathrm{C}$ in air, and ground. The resultant powder was pressed into disks, sintered at 1250 to $1350^{\circ} \mathrm{C}$ in air for 2 hours, ground by wet milling and dried. The compositions and properties of the dielectrics used in this study are shown in Tables 1 and 2. Glass powders and pastes were prepared as described previously. ${ }^{9,10}$ The compositions of the glass used are shown in Table 3. Thick film capacitors were prepared by printing dielectric paste and electrode paste successively onto $\mathrm{Al}_{2} \mathrm{O}_{3}$ substrates with prefired bottom electrodes and cofiring.

Double glass coating, with the crystallized glass layer (Du Pont 8771) under the top amorphous glass layer (HG-1010, our own development), was used in order to passivate the capacitors.

$\dagger$ Revised version of paper originally given at the 2 nd European ISHM conference, Ghent 1979.

\section{RESULTS AND DISCUSSIONS}

\subsection{Characteristic Relationships to Bulk Dielectrics}

Figure 1 shows the dielectric constant $(\epsilon)$ of thick film capacitor materials composed of $\mathrm{BaTiO}_{3}$ family dielectrics and glass as a function of the $\epsilon$ of the raw dielectrics referring to $10 \mathrm{wt} \%$ glass content. The $\epsilon$ of the binary system increases with increasing the $\epsilon$ of the dielectrics. However, a strong trend to saturate is observed when a dielectric with $\epsilon$ more than 3000 is used as a constituent. The major reason for the saturation is the depression of the $\epsilon$ peak at the Curie point caused by the partial reaction between constituents and the dielectric degradation undergone during the grinding process. The $\epsilon$ of this binary system is affected by the kind of binder glass, additives, electrode used and firing temperature. A $\epsilon$ of about 2000 can be obtained by the optimum combination of these factors, but it never exceeds this value. Figure 2 shows the correlation between $\epsilon$ and temperature coefficient of capacitance (TCC) of $\mathrm{TiO}_{2}-\mathrm{MgO}-\mathrm{ZrO}_{2}$ (TMZ) temperature compensating dielectrics and also of the TMZ-glass thick film binary system. As seen in the figure, $\epsilon$ and TCC of the binary system have a close correlation to those of the TMZ used as a constituent.

\subsection{Effect of Glass}

As indicated in Figure 1, the $\epsilon$ of $\mathrm{BaTiO}_{3}$ family dielectrics-glass binary system increases with increasing the $\epsilon$ of the glass. The $\tan \delta$ and TCC of the glass has little effect on those of the binary system. On the contrary, the dielectric properties of the TMZ-glass 
TABLE I

Compositions and properties of high $\epsilon$ dielectrics

\begin{tabular}{|c|c|c|c|c|c|c|c|c|c|}
\hline \multirow[b]{2}{*}{ No. } & \multicolumn{7}{|c|}{ Composition (mol\%) } & \multicolumn{2}{|c|}{ Properties } \\
\hline & $\mathrm{BaO}$ & $\mathrm{CaO}$ & $\mathrm{SrO}$ & $\mathrm{PbO}$ & $\mathrm{TiO}_{2}$ & $\mathrm{SnO}_{2}$ & $\mathrm{ZrO}_{2}$ & $\epsilon$ & $\tan \delta(\%)$ \\
\hline 1 & 47 & $\overline{-}$ & 3 & - & 44.5 & 5.5 & - & 12800 & 2.2 \\
\hline 2 & 43 & 7 & - & - & 43 & 7 & - & 5200 & 1.6 \\
\hline 3 & 44.5 & 3.5 & 2 & - & 43 & 3.5 & 3.5 & 3160 & 2.3 \\
\hline 4 & 50 & - & - & - & 35 & - & 15 & 3040 & 0.7 \\
\hline 5 & 50 & - & - & - & 34 & - & 16 & 3210 & 0.4 \\
\hline 6 & 50 & - & - & - & 50 & - & - & 1800 & 1.0 \\
\hline 7 & 22.5 & - & - & 27.5 & 27.5 & - & 22.5 & 1660 & 1.0 \\
\hline 8 & 22.1 & - & - & 28.4 & 28.5 & - & 22.1 & 1210 & 1.1 \\
\hline 9 & 20.5 & - & - & 29.5 & 29.5 & - & 20.5 & 1070 & 1.1 \\
\hline 10 & 50 & - & - & - & 39.5 & 10.5 & - & 940 & 1.5 \\
\hline 11 & 50 & - & - & - & 40 & 10 & - & 870 & 1.5 \\
\hline 12 & 50 & - & - & - & 40.5 & 9.5 & - & 850 & 1.6 \\
\hline
\end{tabular}

TABLE II

Compositions and properties of low $\epsilon$ dielectrics

\begin{tabular}{|c|c|c|c|c|c|c|}
\hline \multirow[b]{2}{*}{ No. } & \multicolumn{3}{|c|}{ Composition (wt\%) } & \multicolumn{3}{|c|}{ Properties } \\
\hline & $\mathrm{TiO}_{2}$ & $\mathrm{MgO}$ & $\mathrm{ZrO}_{2}$ & $\epsilon$ & TCR(ppm/K) & $Q$ \\
\hline 1 & 85 & 5 & 10 & 110 & -950 & 4130 \\
\hline 2 & 75 & 10 & 15 & 85 & -670 & $>10000$ \\
\hline 3 & 65 & 5 & 30 & 68 & -460 & " \\
\hline 4 & 65 & 15 & 20 & 63 & -320 & $"$ \\
\hline 5 & 65 & 25 & 10 & 56 & -190 & $"$ \\
\hline 6 & 55 & 10 & 35 & 58 & -90 & $"$ \\
\hline 7 & 55 & 30 & 15 & 31 & +50 & 520 \\
\hline 8 & 60 & 40 & 0 & 22 & +100 & 940 \\
\hline
\end{tabular}

TABLE III

Compositions and properties of glass

\begin{tabular}{|c|c|c|c|c|c|c|c|c|c|c|c|c|}
\hline \multirow[b]{2}{*}{ No. } & \multicolumn{9}{|c|}{ Composition (wt\%) } & \multicolumn{3}{|c|}{ Properties } \\
\hline & $\mathrm{PbO}$ & $\mathrm{SiO}_{2}$ & $\mathrm{~B}_{2} \mathrm{O}_{3}$ & $\mathrm{MgO}$ & $\mathrm{BaO}$ & $\mathrm{Na}_{2} \mathrm{O}$ & $\mathrm{Al}_{2} \mathrm{O}_{3}$ & $\mathrm{Bi}_{2} \mathrm{O}_{3}$ & $\mathrm{TiO}_{2}$ & $\epsilon$ & $\mathrm{TCC}(\mathrm{ppm} / \mathrm{K})$ & $Q$ \\
\hline 1 & 8 & 39 & 6 & - & 28 & 6 & 5 & 8 & - & 11 & +190 & 550 \\
\hline 2 & 57 & 16 & 22 & 2 & - & - & 3 & - & - & 14 & +150 & 400 \\
\hline 3 & 11 & 3.5 & 3 & - & 2 & - & - & 80 & 10.4 & 27 & - & 204 \\
\hline 4 & - & - & 2 & - & - & - & - & 93.4 & 4.6 & 65 & - & 55 \\
\hline 5 & - & - & 2.3 & - & 5.2 & - & - & 85.8 & 6.7 & 66 & +310 & 180 \\
\hline 6 & - & - & 2.5 & - & 5.5 & - & - & 83.4 & 8.6 & 70 & +380 & 190 \\
\hline
\end{tabular}




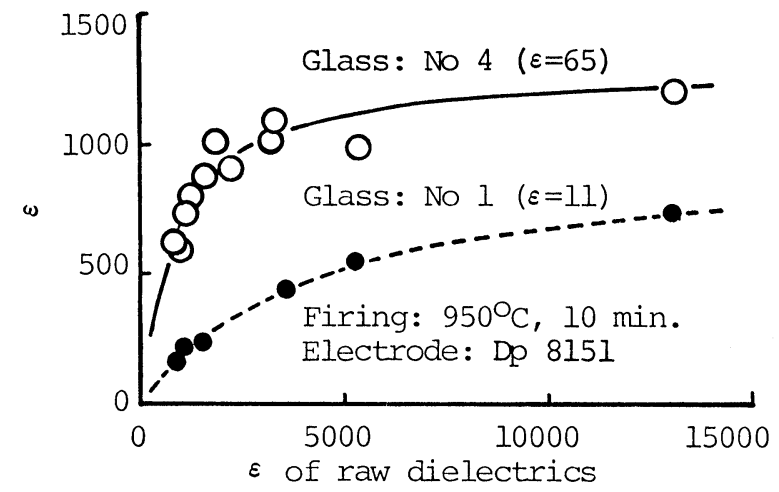

FIGURE $1 \epsilon$ of $\mathrm{BaTiO}_{3}$ family dielectrics-glass as a function of $\epsilon$ of the raw dielectrics.

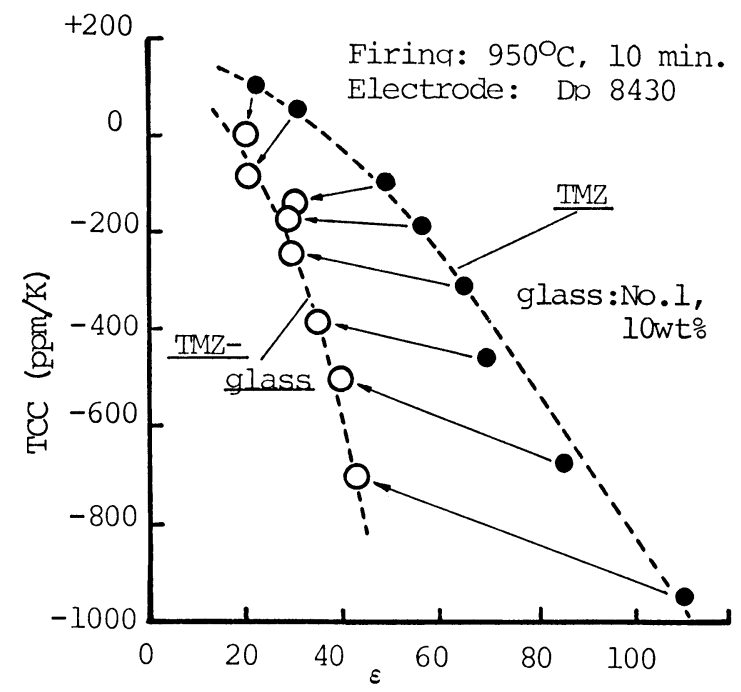

FIGURE 2 Correlation between $\epsilon$ and TCC of TMZ and TMZ-glass binary system.

TABLE IV

Effect of the glass on the dielectric properties of the TMZglass binary system

\begin{tabular}{lllllllll}
\hline & \multicolumn{2}{l}{ Glass } & & \multicolumn{3}{l}{ TMZ-glass } \\
\cline { 2 - 3 } \cline { 6 - 8 } \cline { 6 - 8 } Glass No. $\epsilon$ & TCC $(\mathrm{ppm} / \mathrm{K})$ & $Q$ & & $\epsilon$ & TCC $(\mathrm{ppm} / \mathrm{K})$ & $Q$ \\
\hline 1 & 11 & +190 & 550 & & 35 & -390 & 1890 \\
2 & 14 & +150 & 400 & & 42 & -420 & 1200 \\
5 & 66 & +310 & 180 & & 44 & -310 & 460 \\
6 & 70 & +380 & 190 & & 46 & -260 & 560 \\
\hline
\end{tabular}

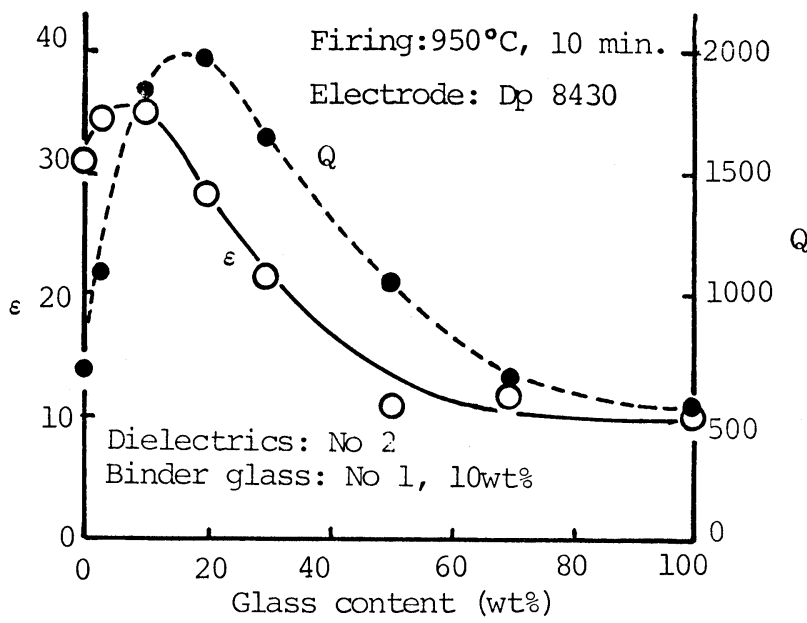

FIGURE 3 Variation of $\epsilon$ and $Q$ of TMZ-glass with glass content.

binary system are affected to a great extent by the properties of the glass as shown in Table 4.

Figure 3 displays the variation of $\epsilon$ and $Q$ with the content of No. 1 glass shown in Table 3. $\epsilon$ and $Q$ of the TMZ-glass exhibit the maximum value at about 10 and $15 \mathrm{wt} \%$ glass content, respectively. The $\epsilon$ of the $\mathrm{BaTiO}_{3}$ family dielectrics-glass binary system also shows a maximum at small glass content, as is already known. Figure 4 shows the variation of TCC of the TMZ glass system with glass content. The TCC of the system seems to be given exactly by simple proportionality from the TCC of the constituents when electrodes without glass binder are used. The TCC

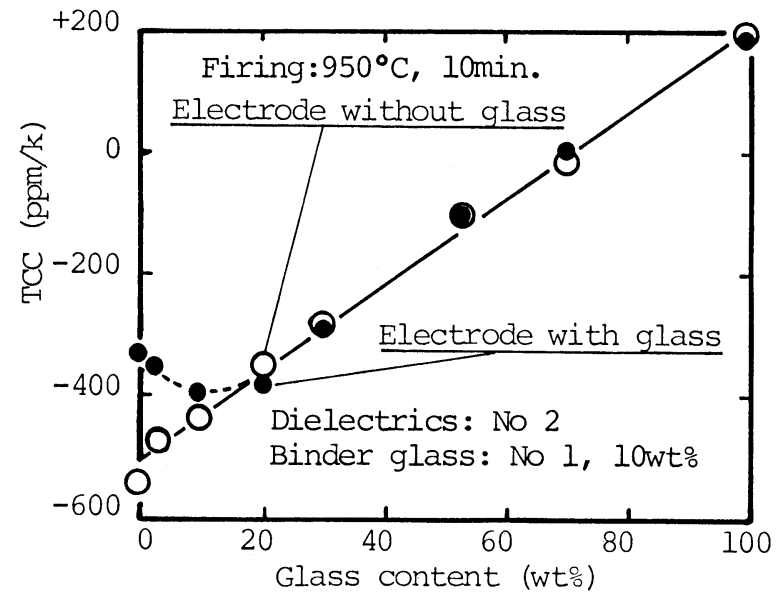

FIGURE 4 Effect of glass content on TCC of the TMZglass system. 
of the glass binder in the electrodes affects the TCC of the system if the system contains less than $20 \mathrm{wt} \%$ of glass.

\subsection{Effect of Electrode}

Table 5 shows the effect of electrodes on the dielectric properties of the TMZ-glass binary system. Electrodes have a predominant influence on the $Q$ of the system. A careful selection of electrodes is necessary in order to fabricate high $Q$ thick film capacitors using the system.

TABLE V

Effect of electrode on the properties of TMZ-glass

\begin{tabular}{lllll}
\hline Electrode & $\epsilon$ & TCC $(\mathrm{ppm} / \mathrm{K})$ & $Q$ & note \\
\hline Dp 8430 & 35 & -390 & 1890 & - \\
CLP-495 & 37 & -408 & $>10000$ & - \\
CLP-579 & 28 & -454 & $>10000$ & no binder glass \\
HC-001 & 27 & -412 & 3300 & no binder glass \\
\hline
\end{tabular}

glass content: $10 \mathrm{wt} \%$, dielectrics: No. 3 in table 2, glass; No. 1 in table 3 , firing $950^{\circ} \mathrm{C}, 10 \mathrm{~min}$.

The $\epsilon$ of the $\mathrm{BaTiO}_{3}$ family dielectric-glass binary system depends on the electrode. The effective $\epsilon$ of the system can be increased by using a high $\mathrm{Ag}$ content electrode. Since the use of such an electrode lowers the initial value of breakdown voltage, this phenomenon may probably correspond to the decrease of true thickness of the dielectric layer by Ag diffusion during firing.
Figure 5 displays the change of breakdown voltage during high temperature load test. This result indicates that high $\mathrm{Ag}$ content electrodes cause the decrease of breakdown voltage of thick film capacitors during operation, even if they are provided with a complete glass passivation.

\subsection{Reliability}

Since the dielectric layer of capacitors fabricated using the binary system is porous and acts like a good absorber of water vapor, the glass passivation is necessary in order to stabilize the electric properties and to prevent $\mathrm{Ag}$ migration of the electrodes.

A double glass coating with an intermediate crystallized glass layer under the top amorphous glass layer is the most appropriate configuration for this purpose. The intermediate layer prevents cracking and penetration of the amorphous glass. The penetration of the amorphous glass into the dielectric layer may cause a decrease of $\epsilon$ due to the chemical reaction between them.

X-ray diffraction patterns of a heat treated mixture of $\mathrm{BaTiO}_{3}$ and HG-1010 reveal the formation of materials with low $\epsilon$ such as $\mathrm{Ba}_{2} \mathrm{TiSi}_{2} \mathrm{O}_{8}$ and $\mathrm{BaTiSiO}_{5}$ as shown in Figure 6.

Figure 7 displays a cross section of the thick film capacitor. As bubbles formed in sintering and fusion process of amorphous glass are raised upto the surface, the layer without the bubbles, no bubble layer is formed. The thickness of the no-bubble layer plays an important role in ensuring reliability. As shown in Figure 8, it is necessary for the thickness of the no bubble layer to be more than $50 \mu \mathrm{m}$ in order to

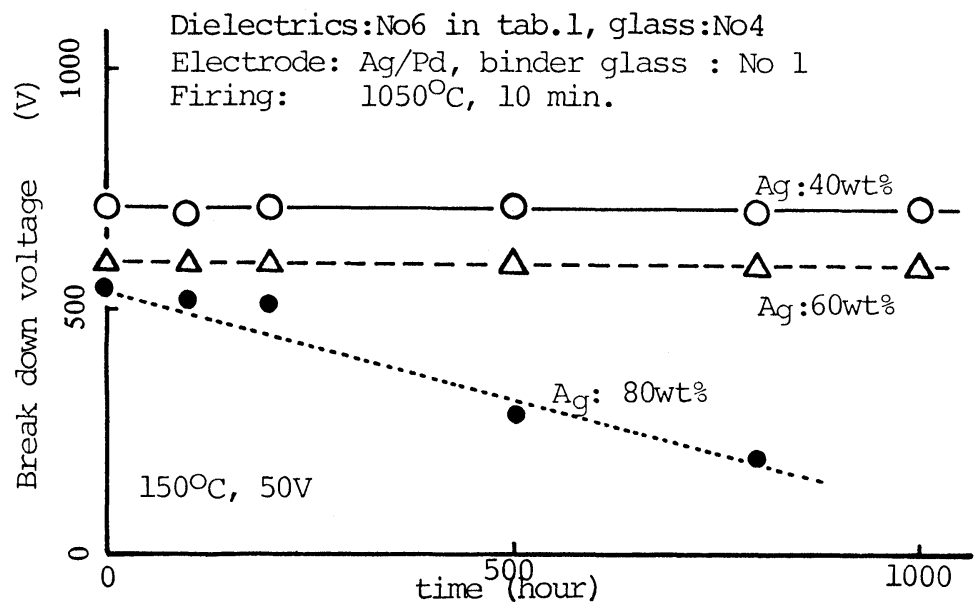

FIGURE 5 Change of break down voltage during high temperature operation test with varying Ag content of electrode. 


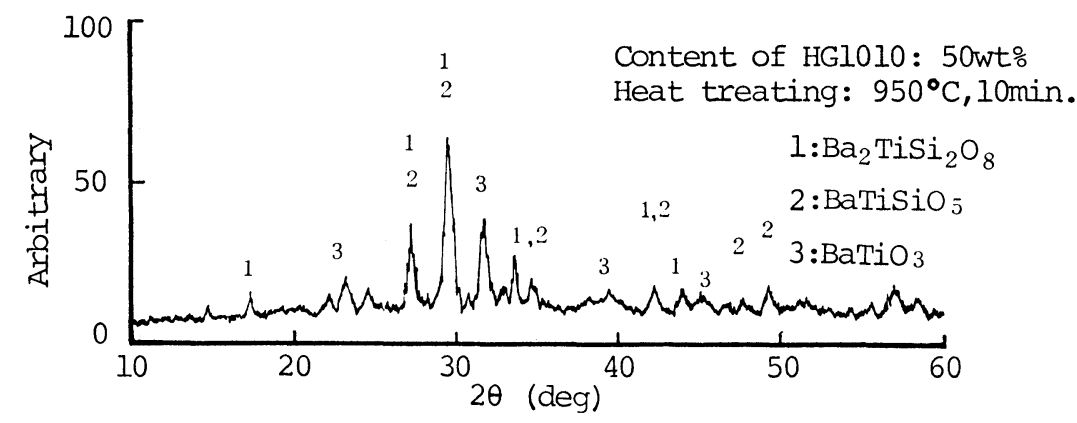

FIGURE 6 X-ray diffraction pattern.

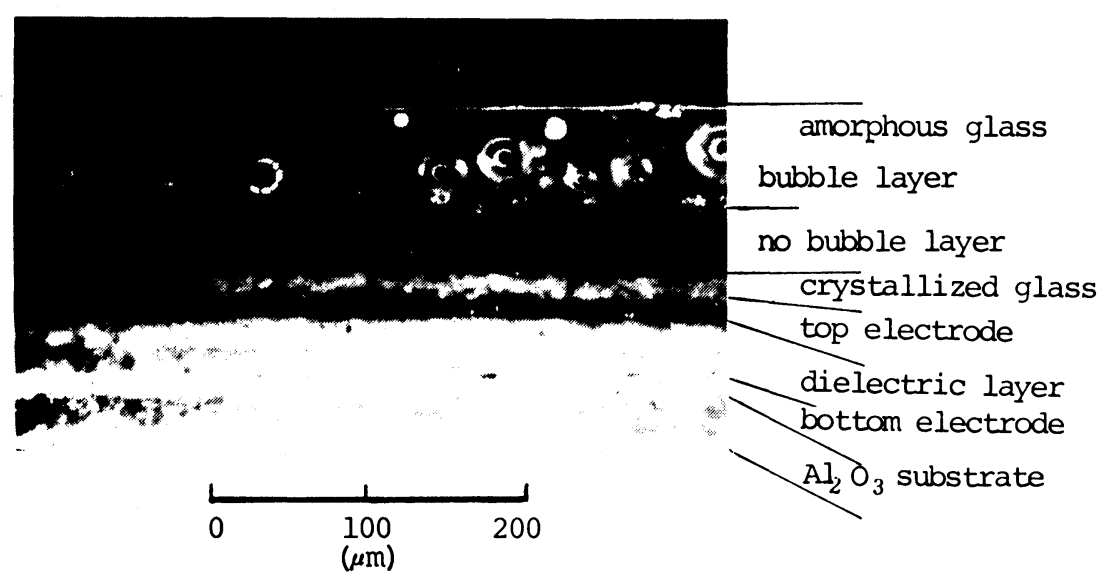

FIGURE 7 Cross section of thick film capacitor.

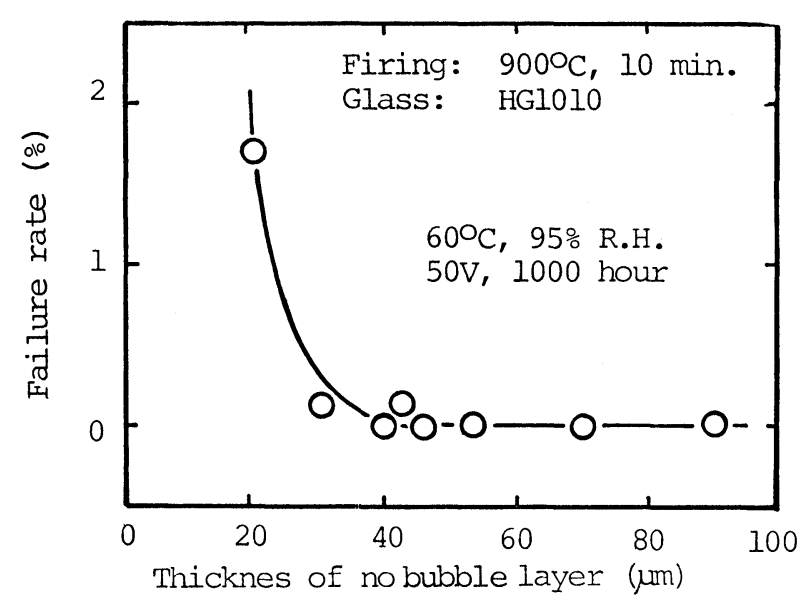

FIGURE 8 Relationship between failure rate and thickness of no bubble layer.

establish high reliability in hybrid ICs with thick film capacitors of the dielectric powder-glass binary system.

\section{CONCLUSION}

1) The dielectric constant of the $\mathrm{BaTiO}_{3}$ family dielectrics-glass binary system never exceeds 2000 even if a dielectric with a dielectric constant of more than 10000 is used as a constituent.

2) The dielectric properties of the TMZ-glass binary system show a close correlation to those of TMZ. Dielectric constants ranging from 20 to 50 , TCC from 0 to $-700 \mathrm{ppm} /{ }^{\circ} \mathrm{C}$ and $Q$ values of more than 10000 are easily obtained in this system.

3) Decrease in the breakdown voltage of capacitors of the dielectric powder-glass binary system is observed during high temperature load test. The decrease can be prevented by the adequate combination of materials.

4) A double glass coating system with over $50 \mu \mathrm{m}$ thick of a no-bubble layer ensures extremely high reliability in thick film capacitors of the dielectric powder-glass binary system. 


\section{REFERENCES}

1. W. R. Bratschum, Glass passivated thick film capacitors for RC circuits, Proc. Electronic Component Conf., pp 304-312 (1976).

2. I. G. Bowkley, Improved glass ceramic thick film capacitors, Proc. Conf. On hybrid microelectronics (1973).

3. M. L. Kummel, A screenable high dielectric constant capacitor system for commercial circuit application, Proc. ECC, pp 124-132 (1972).

4. F. H. Edelman, Some properties of thick film Niobate capacitors, Proc. ECC, pp 40-51 (1970).

5. J. W. Asher and C. M. Pratt, Jr, Screen printed ferroelectric glass-ceramic capacitor, Proc. ECC, pp 239-245 (1968).

6. L. C. Hoffman and T. Nakayama, Screen printed dielec- trics, Microelectronics and Reliability 7, pp 131-135 (1968).

7. J. P. Holden, The development of Glass capacitors for thick film circuit, The Radio and Electronic Engineer 36 , pp 381-387 (1968).

8. R. Borek, B. Licznerski and B. Rzasa, Thick film capacitor with a Rutilium dielectrics, Microelectronics and Reliability 11, pp 551-523 (1972).

9. A. Ikegami, H. Tosaki and T. Mosume, Spinel-Precious metal-glass thick film thermistor paste, Proc. ISHM Symp., pp 287-291 (1966).

10. A. Ikegami and K. Shinriki, Chemical reaction and electrical properties of amorphous $\mathrm{RuO}_{2}$-Ag-Glass ternary system, Proc. European Hybrid Microelectronic Conf., XVII pp 1-7 (1977). Electrocomponent Sci. and Tech. 5, pp 27-32 (1978). 

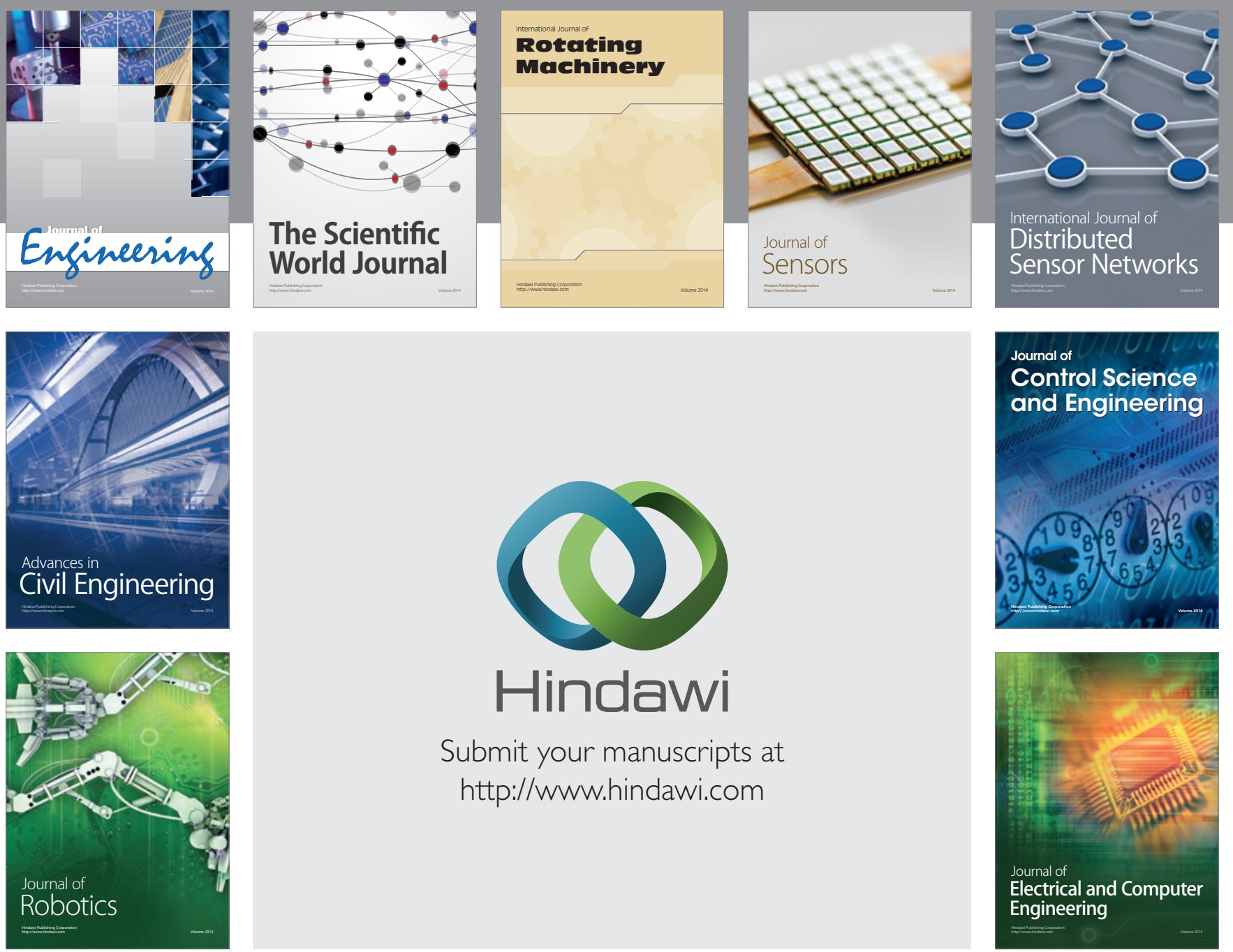

Submit your manuscripts at

http://www.hindawi.com
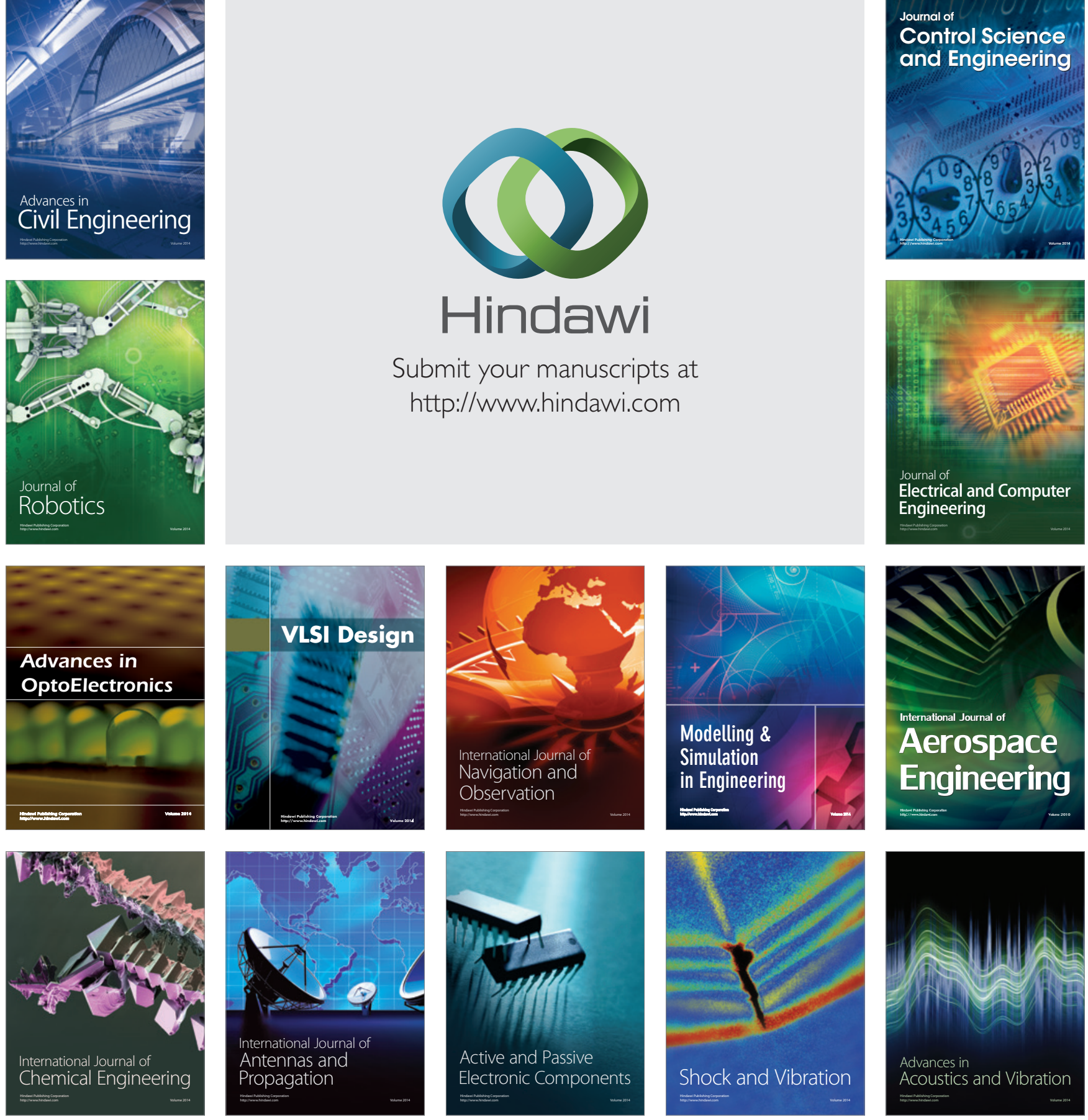